\title{
Conditioned inhibition of exploration in young rats
}

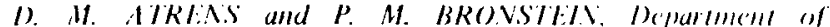

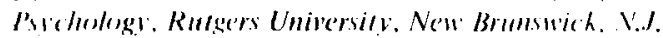

The inhibition of exploratory beharior. and responses to the (S

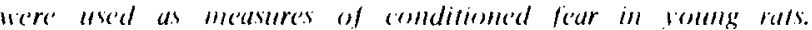
Commarisom wilh comtrol gromps indicale that all cxpericonce

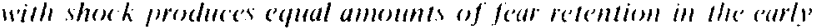
and midalle stagen of axtinction. The differentidel effects produced by the sariom prescedures became alparent enls later in cxtimetion when the gromt) that had expertenced (S-US pairings in acquisition extribited significantly more resideal fear than the controls on both responso measures.

The great majority of the studies on the conditioned emotional response (Cl:R) have used a decrement in the rate of responding for food or water as a measure of the fear elicited by the (S. In the interest of extending the generality of the effects of conditioned emotionality, the present authors have employed another response, exploration. This allows the examination of the effects of fear on the animal's basic response repetoire without the alterations in response thresholds produced by the deprivition regimens necessary to generate other behaviors (Campbell \& Sheffield, 1953). In addition, this behavior may be articulated into several meaningful components for a finer overall resolution of behavior.

Subjects and Apparatus

\section{METHOD}

The Ss were 30, male Sprague-Dawley rats, 23 days old at the start of the experiment. All Ss were housed one to a cage on ad lib food and water.

The apparatus was a Grason-Stadler test chamber using a model E104-GS shock generator-scrambler. The continuous observation data were recorded on cumulative clocks actuated by push-buttons mounted on a small panel in front of the test chamber. The buttons were labeled from left to right, grooming, rearing. locomoting. and inactive.

The CS was a $60 \mathrm{cps}$ buzzer with an intensity of 75-77 dB against a background noise level of $69-71 \mathrm{~dB}$ as measured by a General Radio sound meter set on standard frequency-response curve "C."

Procedure

Six Ss were randomly assigned to each of the five treatment groups. In acquisition. each $S$ in Group 1 was placed in the test chamber where it received $18 \mathrm{I}$ sec simultaneous buzzer-shock $(1$ mA) pairings. spaced at $10 \mathrm{sec}$ intervals. Group 2 was treated similarly except for the buzzer occurring for $1 \mathrm{sec}$ in the middle of each intershock interval. Group 3 received only the shock every 10 sec. Group 4 experienced only the buzzer every $10 \mathrm{sec}$, and Group 5 was merely placed in the test clamber for an identical length of time receiving neither shock nor buzzer.

The extinction sessions. each consisting of 18 CS-only presentations at $10 \mathrm{sec}$ intervals were identical for all groups. Immediate responses to the buzzer were recorded by an observer in the manner of Kimble (1955) and Atrens (1967). Another obscrver made a continuous record of the behavior between CS presentations by depressing the appropriate button for the duration of each unit of behavior. Atrens (1967) has demonstrated that this technicue is highly reliable, yiclding interobserver reliability coefficients of 0.91 and higher. The extinction sessions were conducted 16.20 , and 22 days after acquisition.

\section{RESULTS}

An index of suppression is provided by the inactivity scores which are the compliment of the sum of the other three behavioral categories. An analysis of variance on the inactivity data, which are presented in Fig. 1. yielded significant $(p<.001)$ effects of treatment and days. In addition there was a significant $(p<.05)$ interaction between these two variables.

Separate Duncan's range tests conducted on each day's data indicalled no significint dilterences among the three shock group for the first two lest alas. However. by extinction 1)ay 3, all groups had merged an the level of the nomblocked controls except for (iroup I which still evidenced significantly $(p-0.5)$ more residual suppression. 1he buseronly proup showed less inhibition of exploration on test bat I than the no-stimulus group. This difference vanished in subecfuent test sessions. However. for the first two days both of these nonshocked groups showed much less suppression than the three groups that had experienced shock.

The data on the immediate responses to the buzzer were analyzed in terms of the mein number of buzzer presentations in extinction to the first trial when the buzzer elicited no disruption of ongoing behavior. These data, which are presented in Fig. 2. generally reflect the same process that is seen in the continuous observation data. Here the same $F$ ratios were significant (all at $p<.01)$. The Duncan's range tests, here revealed more clearly $(p<.01)$ the higher residual suppression in Group 1 on the last day of extinction.

\section{DISCUSSION}

Perhaps the most striking implication of these data is that initially, equal amounts of conditioned emotional disruption of exploratory behavior are produced by simultaneous conditioning. $4.5 \mathrm{sec}$ trace-conditioning (this can also be called backward conditioning) and sensitization. Initially, these groups spend an average of only $13 \%$ of their time engaged in any form of active behavior vs an average of approximately $43 \%$ in the two nonshocked control groups. A comparison between the latter two groups on Day 1 affirms the mild aversiveness of the buzzer itself.

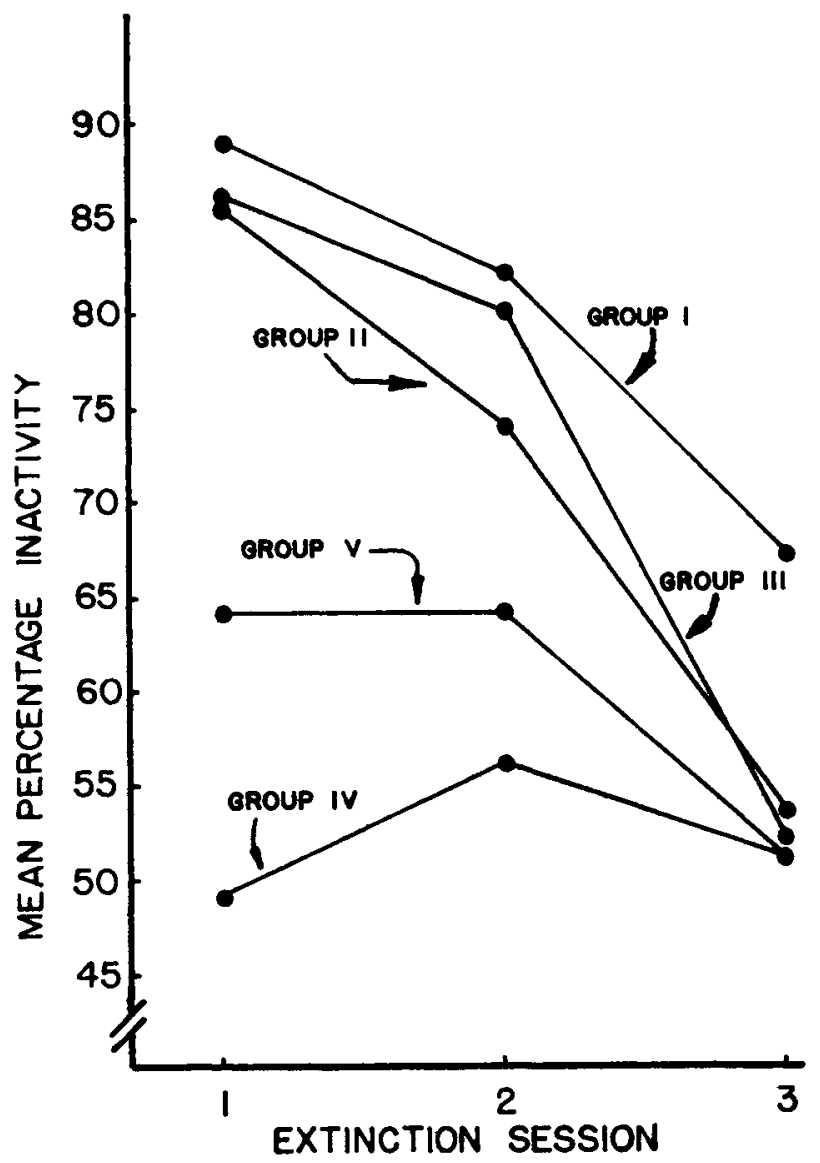

Fig. 1. Mean percentage of inactivity over the three test sessions. 


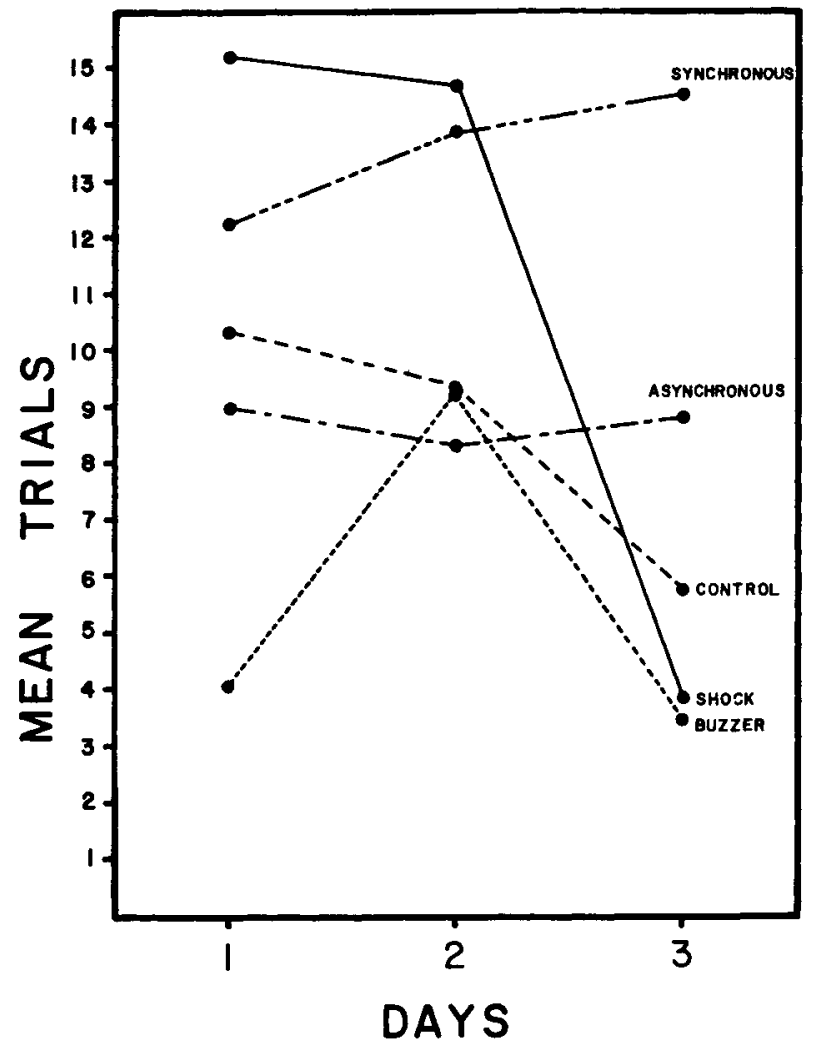

Fig. 2. Mean number of trials till the first non-disnuption of ongoing behavior response to the buzzer.
That the simultaneous conditioning procedure ultimately leads to the retention of more fear than the other procedures does not become apparent until the third extinction session. By this time the other groups are spending $50 \%$ more of their time exploring. In addition, the immediate disruptive effects of the buzzer had diminished to where it now took an average of $5.5 \mathrm{CS}$ presentations before the other groups showed a no-disruption response. On the other hand, Group 1 had not changed significantly from the first test day, still averaging $14.5 \mathrm{CS}$ presentations to the same criterion.

Note that the groups that responded to the CS most vigorously and for the longest time also showed the most inhibition of exploration. Atrens (1967) has also demonstrated that the vigor of response to a US is positively related to the amount of overall suppression of activity. Taken together, these two studies indicate a basic continuity between the behavior elicited by both conditioned and unconditioned aversive stimuli. In either paradigm the strength of the reaction to the aversive stimulus is negatively correlated with the amount of activity that is emitted between stimulus presentations.

\section{REFERENCES}

ATRENS, D. M. An analysis and evaluation of the concept and measurement of general activity in the albino rat. A.M. thesis, Hollins College, 1967.

ATRENS, D. M. Some behavioral effects of inescapable shock. Paper read at E.P.A., Boston, 1967.

CAMPBELL, B. A., \& SHEFFIELD, F. D. Relation of random activity to food deprivation. Journal of Comparative \& Physiological Psychology, $1953,46,320-322$.

KIMBLE, G. A. Shock intensity and avoidance learning. Journal of Comparative \& Physiological Psychology, 1955, 48, 281-284. 